\title{
Creencias y actitudes de los jóvenes universitarios canarios hacia las variedades cultas del español ${ }^{1}$
}

\author{
Clara Eugenia Hernández Cabrera ${ }^{2}$ \\ Marta Samper Hernández ${ }^{3}$ \\ Universidad de Las Palmas de Gran Canaria
}

\begin{abstract}
Resumen
En este artículo exponemos los resultados de la aplicación de la encuesta adoptada por el proyecto PRECAVES XXI a estudiantes canarios del grado de Lengua Española y Literaturas Hispánicas de la Universidad de Las Palmas de Gran Canaria. Nos centraremos fundamentalmente en el análisis de las percepciones que los universitarios canarios muestran hacia su propia variedad, pero también se realizará una aproximación a las diversas valoraciones sobre el resto de las modalidades contempladas en el proyecto. Los resultados, a partir de una metodología que no había sido aplicada en
\end{abstract}

1 Esta publicación forma parte del proyecto de investigación "Estudio complementario de los patrones sociolingüísticos del español de España-Las Palmas de Gran Canaria (ECOPASOS)" (Referencia FFI2015-68171-C5-5-P), financiado por el Ministerio de Economía y Competitividad y por el Fondo Europeo de Desarrollo Regional (FEDER).

2 Para correspondencia, dirigirse a: Clara Eugenia Hernández Cabrera (claraeugenia. hernandez@ulpgc.es), Facultad de Filología, Edificio de Humanidades, Universidad de Las Palmas de Gran Canaria. C/ Pérez del Toro 1, 35003, Las Palmas de Gran Canaria, España.

3 Para correspondencia, dirigirse a: Marta Samper Hernández (marta.samper@ulpgc.es), Facultad de Filología, Edificio de Humanidades, Universidad de Las Palmas de Gran Canaria. C/ Pérez del Toro 1, 35003, Las Palmas de Gran Canaria, España. 
el estudio de las actitudes del hablante canario, aportan novedades importantes en relación con trabajos previos.

Palabras clave: español de Canarias, creencias lingüísticas, actitudes lingüísticas, PRECAVES XXI, sociolingüística hispánica, variedades del español.

\title{
Beliefs ANd atTitudes of Young CANARIAN university STUdents TOWARDS THE EDUCATED VARIETIES OF SPANISH
}

\begin{abstract}
In this article, we shall present the results obtained from the survey carried out within the framework of the PRECAVES XXI project, which was implemented with 117 Canarian students from the degree in 'Spanish Language and Hispanic Literatures' at the University of Las Palmas de Gran Canaria. We will focus especially on the perceptions of Canarian university students towards their own linguistic variety, but we will also highlight the different evaluations they offer for the other modalities which are included in the project. The results, obtained by means of a methodology that had not been employed until now for the analysis of Canarian speakers' attitudes, provide us with important novelties in relation to previous research.

Keywords: Spanish spoken in the Canary Islands, linguistic beliefs, linguistic attitudes, PRECAVES XXI, Hispanic Sociolinguistics, Spanish varieties.
\end{abstract}

Recibido: 08/03/2018 Aceptado: 23/04/2018

\section{INTRODUCCIÓN}

El trabajo actual resulta novedoso entre las investigaciones sobre el español de Canarias, puesto que adopta una metodología de carácter cuantitativo para el estudio de las actitudes de los hablantes de la región hacia su propia variedad y hacia otras del mundo hispánico a partir de un cuestionario común que se está aplicando en un importante número de comunidades de habla en España e Hispanoamérica, dentro del proyecto PRECAVES XXI. Además del citado carácter cuantitativo, debemos destacar que las actitudes se extraen fundamentalmente a partir del análisis de enunciados 
orales que realizan los encuestados. Este aspecto metodológico ${ }^{4}$ permite obtener resultados muy iluminadores; a lo largo de nuestro trabajo, hemos de comprobar si se produce una valoración diferente cuando se pregunta a los informantes, de una forma general, dónde se habla mejor el español y cuando se les pide que valoren textos orales concretos emitidos por hablantes cultos de cada variedad.

Es cierto que se cuenta con valiosas opiniones acerca de la consideración de los hablantes canarios respecto a su modalidad y sus rasgos peculiares, pero hasta ahora no se dispone de un estudio abarcador ${ }^{5}$, basado en un cuestionario que incorpore la audición de enunciados y con datos cuantitativos objetivos, sobre las actitudes de los hablantes canarios que pueda contrastar lo expuesto por los estudiosos.

Las ideas más reiteradas en la bibliografía de que disponemos insisten en que el canario tiene una visión negativa de su propia habla, padece un complejo lingüístico que se manifiesta a la hora de utilizar y valorar su modalidad dialectal. Esa actitud negativa puede ser explicada a partir de la consideración que han expuesto distintos estudiosos sobre el español de Canarias. En las escasas líneas que dedicó García de Diego en su manual de dialectología española a esta variedad se puede leer: "la lengua fundamental de Canarias es el castellano arcaico y vulgar, en su léxico y en su morfología. Abundan voces como melesina 'medicina', y formas flexivas, como semos, trujo, vide, quedré, que son comunes con el castellano popular" (1978 [1946]: 367). Por otra parte, Catalán, que fue profesor en la Universidad de La Laguna en los años cincuenta del siglo pasado, habló de una confrontación de normas que influye negativamente en la actuación lingüística del isleño, sobre todo en las manifestaciones escritas:

Por lo común una formación primaria y secundaria bastante deficiente no ha bastado para dotar al hombre culto canario de un dominio de la lengua escrita que le permita expresarse en ella con corrección y soltura; así, incluso la minoría pretendidamente selecta de estudiantes y licenciados universitarios (sin excluir los de letras) suele enredarse en la enorme maraña constituida por la dualidad mal percibida de normas lingüísticas (1989 [1964]: 155).

\footnotetext{
4 Tanto la metodología general como el marco teórico del proyecto han sido expuestos en Cestero Mancera y Paredes García 2018, artículo que encabeza este número monográfico.

5 En los últimos años se han llevado a cabo una serie de estudios parciales, memorias de grado o de máster, que han aplicado encuestas a un número reducido de hablantes. El más relevante de ellos es el realizado por Johannessen-Toft (2007).
} 
Fue muy importante un artículo de principios de los años 80 en el que Trujillo señala que el hablante isleño tiene un "sentimiento de escaso prestigio, de inferioridad cultural y social" (1981:16). La inexistencia de una norma lingüística regional homogénea ${ }^{6}$, según este estudioso, ha hecho del canario un hablante inseguro, que tiene conciencia de su torpeza verbal y conceptual: el canario tiene "la convicción de que no sabe hablar, lo que le hace sentirse disminuido frente al hablante peninsular, siempre seguro del lenguaje que emplea, por más bravatas lingüísticas que profiera" (1981:16).

También Ortega Ojeda afirma que “... el hablante de las islas, a través de algunos comportamientos, que, sin ser generales, sí son frecuentes, manifiesta tener un concepto más bien negativo de su «modo de hablar»" (1981:112). En un trabajo posterior, Ortega Ojeda señala lo siguiente:

la inexistencia de una norma lingüística culta prestigiosa [...] supone que los hablantes canarios en general [...] acusen de manera especial en las situaciones formales una inseguridad lingüística considerable, esto es, un frecuente titubeo que $[\ldots]$ hace fluctuar a los usuarios entre sus formas genuinas y las formas características del español peninsular estándar, estas últimas insistentemente aireadas por los medios de comunicación modernos (1996: 66-67).

Morera, por su parte, indica que "el canario siempre ha sentido todas sus modalidades dialectales como formas de hablar inferiores. Para la mayor parte de la gente de las Islas, el único registro lingüístico prestigioso es el español de la Península" (1990: 121). Por eso, en el terreno léxico, según este estudioso, "las palabras de la norma estándar han sido consideradas como los únicos elementos nobles y prestigiosos de la lengua" (1995: 50).

Del amplio trabajo elaborado por Morgenthaler García (2008), que persigue conocer la opinión de los hablantes canarios frente a la estandarización a partir de 54 grabaciones $^{7}$ en que utiliza el método de la entrevista narrativa, extraemos las siguientes conclusiones:

(1) Los hablantes canarios valoran negativamente la norma peninsular, es decir, se ha debilitado el tradicional prestigio de que gozaba aquella en las

\footnotetext{
6 Como forma de paliar ese estado de cosas, Trujillo (1981:23-24) hace una propuesta de seis rasgos fónicos que debería alcanzar la norma culta canaria para adquirir unidad y fijeza.

743 entrevistas individuales (a 22 mujeres y 21 hombres de todas las islas, con la excepción de El Hierro), 8 grupales ( 6 de dos personas y 2 de "más de dos personas") y 3 "conversaciones naturales". Del total de grabaciones, 41 se realizaron en la isla de Tenerife y el resto en Gran Canaria (si bien no se seleccionaron todas para el análisis).
} 
Islas. Los hablantes se resisten al proceso de asimilación y convergencia hacia la variedad estándar; la razón del rechazo se situaría, en el papel fundamental que desempeña la variedad lingüística propia como rasgo identificador de grupo. No existe aún, según la autora, un estándar regional que pudiera servir como modelo prestigioso para los hablantes canarios ${ }^{8}$, aunque existan bases -teóricas, sociales y lingüísticas- para su establecimiento.

(2) Se constata en los hablantes canarios una actitud contradictoria hacia su propia variedad porque, por un lado, se está produciendo un cambio que los lleva a una valoración más positiva de su modalidad considerándola "prestigiosa" (de forma opuesta, según la propia investigadora, a lo que en su momento habían señalado Trujillo, Ortega o Morera) y, por otro, se percibe en muchos de sus informantes el mantenimiento, de forma encubierta, de un "alto grado de inseguridad lingüística" basado en la idea de que su variedad puede resultar "inferior, mal hablada o incorrecta". El análisis de Morgenthaler García le permite afirmar que el cambio hacia una actitud más positiva se puede observar en los ámbitos académico, político e institucional, y entre los propios hablantes, aunque no es tan evidente en los medios de comunicación.

En relación con este uso del español canario en los medios de comunicación se ha de recordar lo que indica Hernández Hernández:

[...] se desprende que la norma más extendida en los medios implantados en Canarias es la castellana, pues es la dominante de los medios lingüísticamente más influyentes, que son la radio y la televisión. [...] No es extraño, por lo tanto, que se tienda a considerar que existe coincidencia entre norma ejemplar del español y norma castellana, pues audiencia y radioyentes tienden a identificar lo normal y lo correcto con lo castellano. [...] Todo esto da lugar, en la lengua hablada, sobre todo, a actitudes de desorientación normativa entre algunos profesionales canarios de los medios de comunicación ${ }^{9}$ (2009: 42).

Con respecto al ámbito académico, Samper Padilla señala lo siguiente:

\footnotetext{
8 Opinión que, como hemos visto, coincide con la expresada por Trujillo, Ortega y Morera.

9 Vid., en este sentido, los trabajos sobre los usos dialectales en los medios de comunicación isleños de Samper Padilla y Hernández Cabrera (2007, 2011), Hernández Cabrera y Samper Hernández (2011) y Hernández Cabrera y Samper Padilla (2018).
} 
En general, el sistema escolar transmite los rasgos propios del español canario culto. Se mantienen los rasgos fónicos generales que son característicos de la modalidad dialectal (por ejemplo, no se evita el seseo ni se trata de pronunciar velar la / $\mathrm{x} /$ ) y se corrigen los fenómenos fónicos estigmatizados socialmente como la neutralización $-\mathrm{r} /-1$ o la frecuente elisión de las consonantes implosivas. En el terreno gramatical, además de la evidente corrección de ciertos rasgos verbales considerados vulgares en amplias zonas del español (cantemos por cantamos, por ejemplo), no está claro el comportamiento de los docentes ante otros fenómenos como el uso variable del adverbio medio, la construcción se los (por se lo) o el empleo personal de haber. Realmente faltan aún estudios de conciencia y actitudes sobre estos hechos, e incluso carecemos de investigaciones empíricas que muestren con claridad cuál es el alcance social de algunos de ellos, si bien es cierto que rasgos como los tres antes citados se pueden escuchar a hablantes cultos canarios (2008: 173).

Lo indicado por los estudios que hemos señalado puede completarse con la visión que sobre la modalidad dialectal se recoge en trabajos de actitudes realizados fuera de las Islas, como los de Bentivoglio y Sedano (1999) y Blas Arroyo (2005). Entre las conclusiones del primer estudio, destacamos que el español canario fue reconocido por el $64 \%$ de los madrileños, pero solo por el $31 \%$ de los caraqueños, que identificaron en gran medida el habla de Las Palmas de Gran Canaria con la de La Habana; ni en Madrid ni en Caracas es seleccionado entre los dialectos que gustan más (ni entre los que gustan menos). Los jóvenes valencianos encuestados por Blas Arroyo valoran mejor al hablante septentrional que al canario en competencia personal y estatus socioeconómico, así como en aquellos parámetros que tienen que ver con el éxito profesional; en cambio, el canario obtiene unas puntuaciones superiores en los rasgos asociados a cualidades humanas y a la integridad. El proyecto PRECAVES XXI, con la aplicación de una misma encuesta en diferentes comunidades, aportará una información necesaria en este sentido.

Nuestra contribución actual ofrecerá algunos resultados de la investigación que estamos realizando en Las Palmas de Gran Canaria. Aunque el presente estudio se centra fundamentalmente en las percepciones que los universitarios canarios muestran hacia su propia variedad, también se realizará una aproximación a las diversas valoraciones sobre el resto de las modalidades contempladas en el proyecto. 


\section{METODOLOGÍA ${ }^{10}$}

Para este estudio se ha partido de una muestra conformada por 117 encuestas aplicadas a estudiantes del Grado en Lengua Española y Literaturas Hispánicas de la Universidad de Las Palmas de Gran Canaria. Estas encuestas fueron realizadas en el aula de informática de la Facultad de Filología durante los años 2014, 2015 y 2016; para el análisis no se han tenido en cuenta los resultados de los estudiantes Erasmus, así como tampoco los de aquellos que procedían de otras zonas hispanohablantes.

La configuración de la muestra atiende a los factores sexo, edad y tipo de colectivo según su formación en el campo de la variación geográfica y social:

\begin{tabular}{|l|l|c|c|}
\hline \multirow{2}{*}{ Sexo } & Hombres & 33 & $28,2 \%$ \\
\cline { 2 - 4 } & Mujeres & 84 & $71,8 \%$ \\
\hline \multirow{2}{*}{ Edad } & Hasta 24 años & 92 & $78,6 \%$ \\
\cline { 2 - 4 } & A partir de 25 años & 25 & $21,4 \%$ \\
\hline \multirow{2}{*}{ Formación en variedades } & Sin formación & 69 & $59 \%$ \\
\cline { 2 - 4 } & Con formación & 48 & $41 \%$ \\
\hline
\end{tabular}

Tabla 1. Configuración de la muestra

En total, estos 117 sujetos valoraron 1872 grabaciones (16 cada uno), correspondientes a las ocho variedades del español que se contemplan en el proyecto, como se ha especificado en el primer artículo de este volumen, así como en Cestero Mancera y Paredes García (2015), y respondieron a preguntas relacionadas con tres aspectos fundamentales: el prestigio de las distintas variedades, la valoración de la variedad propia, y la identificación y valoración de las otras modalidades dialectales.

10 Como ya se indicó anteriormente, la metodología de este trabajo se ajusta a los criterios indicados por Cestero Mancera y Paredes García 2018, dentro de este mismo volumen. 


\section{RESULTADOS}

\subsection{Percepción sobre el PRestigio de las variedades del español}

Es importante este primer apartado en que se recogen las respuestas a la pregunta general abierta "¿Dónde cree que se habla mejor el español?" porque va a reflejar la opinión que tienen los encuestados antes de pasar a la audición de las voces representativas de cada variedad (lo que constituye la parte medular de la prueba). De este modo, podrá comprobarse si las respuestas siguientes, dadas después de escuchar las grabaciones, corroboran o no esa impresión inicial que tienen los informantes. Interesa especialmente esta constatación en una zona en que, como hemos visto en la introducción, parece que predomina una actitud negativa ante la propia modalidad.

El gráfico 1 permite comprobar que el 43,6\% de los sujetos de nuestra muestra consideran que la variedad más prestigiosa es la castellana. En una proporción bastante menor aparece la opción que alude a la igualdad entre todas las variedades (con un $23,9 \%$ ), mientras que solo un $17,7 \%$ cree que el canario es la modalidad más prestigiosa.

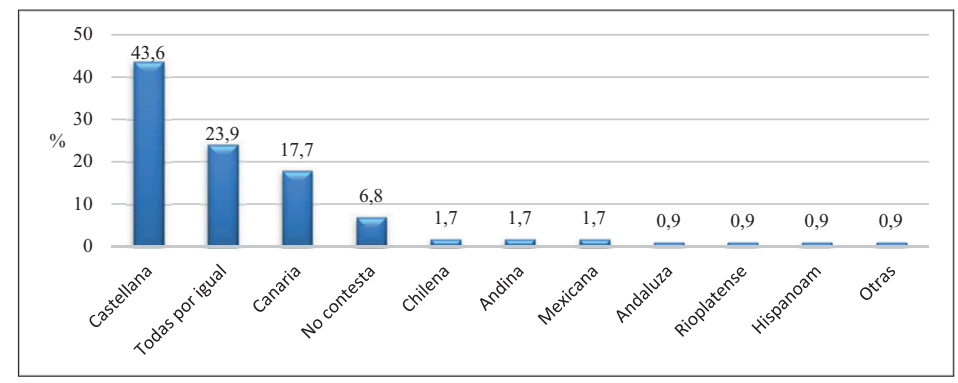

Gráfico 1. Porcentajes que alcanzan las distintas variedades en la pregunta “¿Dónde cree que se habla mejor el español?”

Son datos de interés, que han de contrastarse con los resultados que se obtengan en otras comunidades. Lo relevante es que nuestros estudiantes del Grado de Lengua Española y Literaturas Hispánicas siguen considerando la castellana como la norma de más prestigio entre todas las hispánicas, algo esperable si se tienen en cuenta las opiniones recogidas en la introducción. Destacan asimismo los bajos porcentajes que alcanzan todas las variedades 
hispanoamericanas (ninguna de ellas supera el 1,7\%), debidos probablemente a la lejanía geográfica ${ }^{11}$.

Cuando se atiende a las diferentes variables sociales, se comprueba que la formación de los informantes influye de manera importante en las respuestas. De esta forma, prácticamente la mitad (el 49,3\%) de los sujetos que no han recibido unas enseñanzas específicas de dialectología o sociolingüística opina que el castellano es la norma de prestigio, mientras que los que ya han cursado dichas asignaturas (o al menos alguna de ellas) presentan unos porcentajes más igualados entre esa opción, que sigue siendo la mayoritaria (con un $34,8 \%$ ), y la que aboga por una igualdad entre las variedades. También hay que destacar la alta proporción de estudiantes con formación en estas materias que no han contestado a la pregunta, algo que quizás podría unirse a la consideración de que no existe una única norma de prestigio. Si se sumaran ambos porcentajes, encontraríamos que un $36,9 \%$ de los estudiantes con conocimientos de este tipo no se decantan por una variedad concreta. Los resultados obtenidos en esta pregunta abierta parecen confirmar la importancia de una adecuada formación acerca del pluricentrismo del español -que debería iniciarse ya en las enseñanzas preuniversitarias- para que los hablantes de modalidades tradicionalmente no prestigiosas dejen de considerar únicamente la variedad castellana como el modelo al que se debe aspirar.

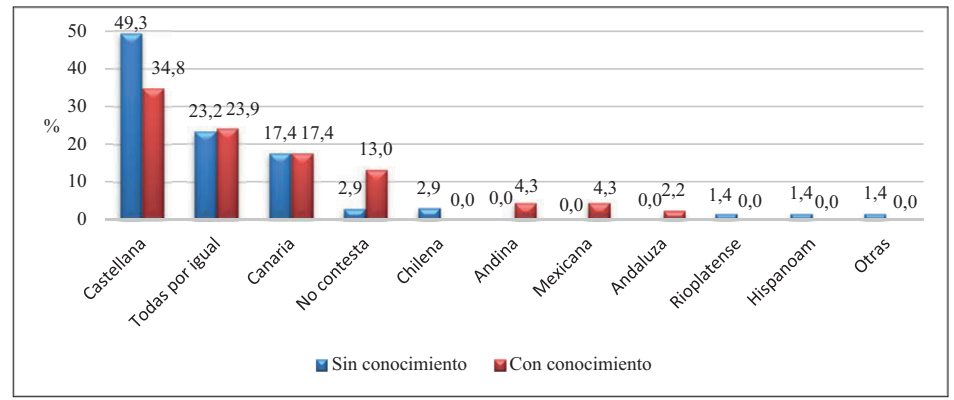

Gráfico 2. Porcentajes que alcanzan las distintas variedades en la pregunta “¿Dónde cree que se habla mejor el español?” según la variable formación en variedades

En lo que se refiere al sexo de los sujetos encuestados, las mujeres parecen tener una mayor seguridad en su idea de prestigio, ya que un $46,4 \%$, casi la

11 Es un resultado que coincide con la dificultad de evaluar variedades cuyos hablantes se desconocen (Buzón García, Gómez Devís y Gómez Molina 2017: 50). 
mitad, opina que la variedad más prestigiosa es la castellana, frente al $36,4 \%$ de los hombres; también destaca el grupo femenino por la consideración de la modalidad canaria como la más prestigiosa, mientras que solo un $4,8 \%$ deja la pregunta sin respuesta. Los hombres, por su parte, se comportan de manera más prudente y en un $12,1 \%$ evitan responder a la pregunta. Ambos grupos ofrecen, por último, unos porcentajes prácticamente idénticos en la opción que defiende la igualdad entre las variedades del español.

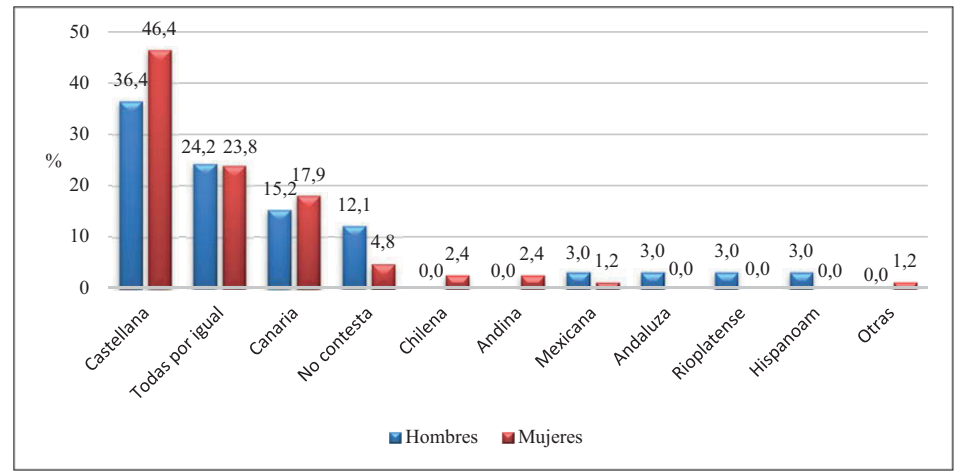

Gráfico 3. Porcentajes que alcanzan las distintas variedades en la pregunta “¿Dónde cree que se habla mejor el español?” según la variable sexo

La variable edad nos ofrece, finalmente, la mayor equivalencia entre los dos grupos en los que se ha dividido la muestra. Los informantes que se inclinan por la variedad castellana presentan porcentajes muy cercanos: $43,5 \%$ entre los más jóvenes y 44\% entre los mayores; sí se puede hablar de una cierta diferencia en cuanto a la visión igualitaria de todas las modalidades, ya que son los informantes de más edad los que defienden esta opción en mayor medida (en un $28 \%$, frente al $22,8 \%$ de los jóvenes). En cualquier caso, debe tenerse en cuenta que la diferencia de edad entre ambos grupos es muy reducida; resultaría de interés cotejar nuestros datos con los que se obtuvieran de la aplicación de la misma encuesta a informantes de la tercera generación, por ejemplo. Eso nos permitiría comprobar si, como ha señalado Morgenthaler García (2008: 388), se ha producido un cambio de actitud en los hablantes canarios. 


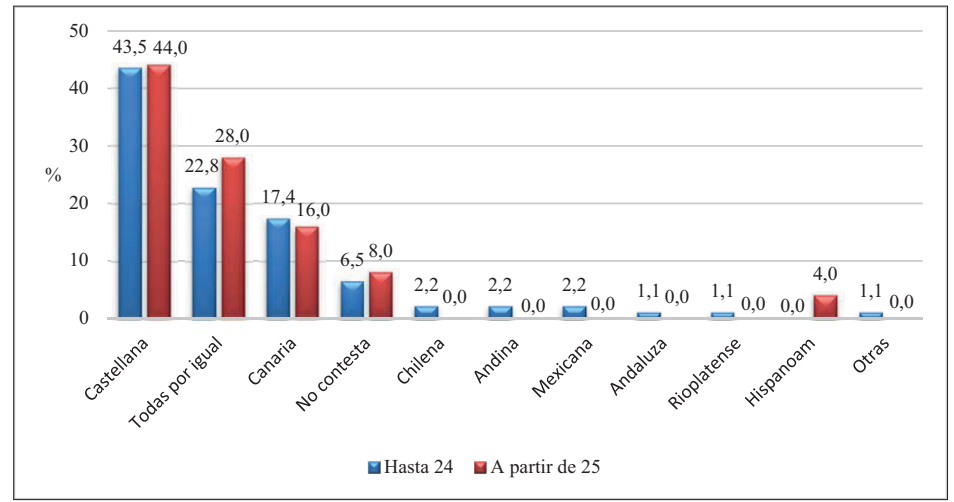

Gráfico 4. Porcentajes que alcanzan las distintas variedades en la pregunta “¿Dónde cree que se habla mejor el español?”según la variable edad

\subsection{PERCEPCIÓN DE LA VARIEDAD PROPIA}

Uno de los objetivos principales del proyecto es comprobar la percepción que tienen los hablantes sobre su propia variedad, aspecto al que se dedicarán las siguientes páginas. Para llegar a conclusiones fiables, lo primero que debemos hacer es excluir del análisis aquellos casos en que los informantes no reconocieron estar escuchando su modalidad. Ha de partirse, por lo tanto, del total de las identificaciones correctas, ya que es en ellas donde los sujetos de la muestra evalúan conscientemente su variedad dialectal.

De las 234 valoraciones posibles, podemos tomar en consideración las $206(88 \%)$ en que se identificaron correctamente las grabaciones de los hablantes canarios. De las 28 ocasiones en que los encuestados no reconocieron su modalidad dialectal (un $12 \%$ del total), en nueve casos $(32,1 \%)$ se consideró que estos sujetos procedían de otros lugares como Argentina, Andalucía, el Caribe, Chile e incluso que eran castellanos, mientras que en otros 14 (50\%) se dieron respuestas amplias como España o Hispanoamérica. Finalmente, en cinco casos (17,9\%) no se aportó ninguna respuesta sobre la procedencia de los hablantes.

Consideramos también importante destacar que se han producido 61 identificaciones de otras variedades como canarias (un 3,7\% sobre el total de las 1638 grabaciones de hablantes no canarios evaluadas por los informantes de nuestra muestra). En la tabla 2 se ofrecen los datos correspondientes: 


\begin{tabular}{|l|c|c|}
\hline \multicolumn{1}{|c|}{ Procedencia } & N & \% \\
\hline Andinas & 1 & 1,6 \\
\hline Caribeñas & 6 & 9,8 \\
\hline Andaluzas & 25 & 41 \\
\hline Chilenas & 29 & 47,5 \\
\hline TOTAL & 61 & \\
\hline
\end{tabular}

Tabla 2. Voces identificadas erróneamente como canarias

De las tres variedades que más veces se han identificado como canarias, llama la atención que solo 6 correspondan a voces caribeñas, dada la cercanía que tradicionalmente se ha atribuido a ambas modalidades. Ahora bien, cuando se atiende al grado de identidad que los informantes atribuyen a las diferentes voces con respecto a su propia variedad, vemos que el $100 \%$ de los que identifican las voces caribeñas como canarias las consideran bastante iguales o totalmente idénticas (tabla 3); en las voces chilenas y andaluzas, sin embargo, se encuentra una mayor variedad de respuestas, aunque siempre predomina la igualdad (por encima de un 65\%). Por lo tanto, aunque en los datos más generales no se haya encontrado la esperable mayor semejanza con el Caribe, sí se demuestra ahora con estas respuestas la identificación que hacen los hablantes de dos zonas dialectales tradicionalmente relacionadas desde los primeros siglos de la expansión atlántica de Castilla.

\begin{tabular}{|l|c|c|c|c|}
\hline Grado identidad & Chilena (29) & Andaluza (25) & Caribeña (6) & Andina (1) \\
\hline Totalmente idéntica & $37,9 \%$ & $28,0 \%$ & $16,7 \%$ & $0,0 \%$ \\
\hline Bastante igual & $27,6 \%$ & $40,0 \%$ & $83,3 \%$ & $0,0 \%$ \\
\hline Ligeramente igual & $13,8 \%$ & $16,0 \%$ & $0,0 \%$ & $0,0 \%$ \\
\hline Ligeramente diferente & $17,2 \%$ & $8,0 \%$ & $0,0 \%$ & $100,0 \%$ \\
\hline Bastante diferente & $3,4 \%$ & $8,0 \%$ & $0,0 \%$ & $0,0 \%$ \\
\hline Totalmente diferente & $0,0 \%$ & $0,0 \%$ & $0,0 \%$ & $0,0 \%$ \\
\hline
\end{tabular}

Tabla 3. Grado de identidad con las voces identificadas erróneamente como canarias 
Una vez delimitadas las encuestas con las que efectivamente vamos a trabajar, pasamos a responder a la siguiente pregunta: ¿Qué percepción tienen los sujetos estudiados de su propia variedad (en este caso la canaria)? Para dar respuesta a esta cuestión se han utilizado tanto preguntas directas como indirectas (se valora la variedad a través de la persona que habla o a través de la región y la cultura). Empezaremos el análisis por las cuestiones directas.

\subsubsection{Valoración directa de la variedad}

En esta serie de preguntas formuladas de manera directa, se emplea una escala de 6 grados formada por adjetivos opuestos que se refieren tanto a aspectos afectivos como cognitivos. Los resultados generales se presentan en el siguiente gráfico:

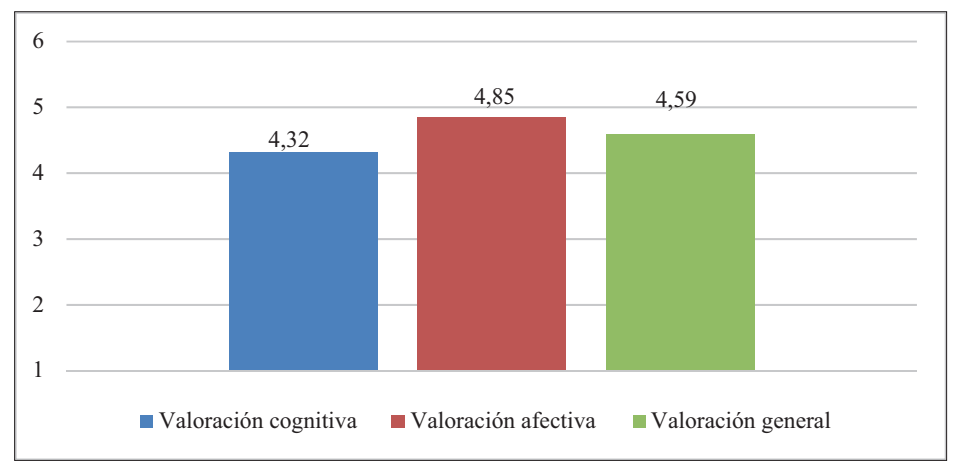

Gráfico 5. Valoración directa sobre la variedad propia

Como se puede observar, la valoración general que los informantes canarios tienen sobre su propia variedad puede considerarse alta (con un 4,59 de media), si bien hay que precisar que la afectiva resulta superior a la cognitiva.

El gráfico 6 refleja los aspectos cognitivos que se han tenido en cuenta y sus correspondientes promedios: 


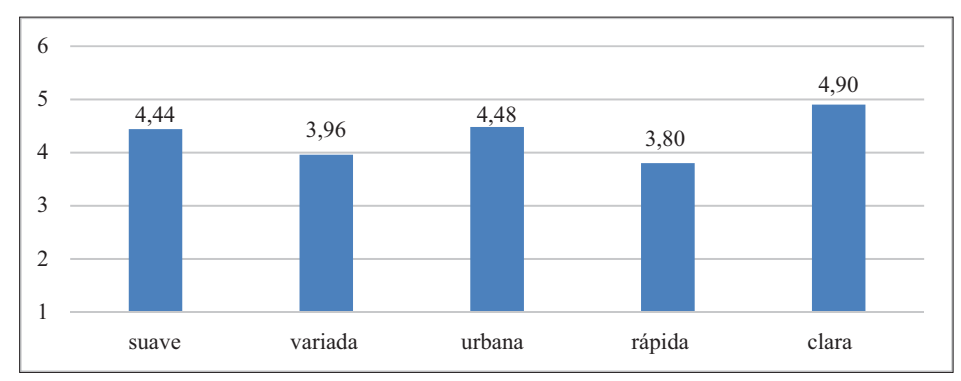

Gráfico 6. Valoración directa sobre la variedad propia. Aspectos cognitivos

Se comprueba que los informantes universitarios canarios consideran que su variedad es clara y también, aunque en menor grado, urbana y suave, si bien los promedios no llegan en ningún caso a los cinco puntos. En el lado opuesto destacan las cualidades de la lentitud y la monotonía, características que pueden relacionarse directamente con el tópico del "aplatanamiento" que se le atribuye al canario.

En lo que respecta a los aspectos afectivos, las cualidades se distribuyen de la siguiente manera:

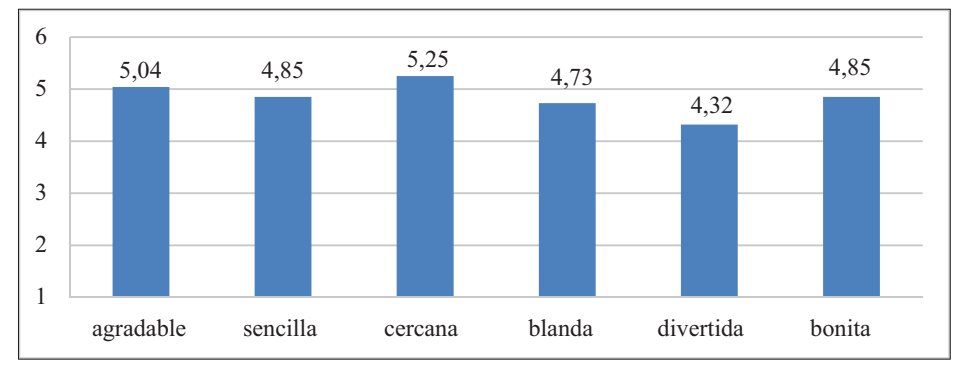

Gráfico 7. Valoración directa sobre la variedad propia. Aspectos afectivos

Dentro de la valoración altamente positiva que alcanzan los aspectos afectivos, se comprueba que las voces de los hablantes resultan, por este orden, cercanas, agradables, bonitas y sencillas. En el extremo contrario, aunque con un 4,32 de promedio, se sitúa el que las voces parezcan divertidas.

Cuando se contemplan por separado las valoraciones sobre la voz femenina y sobre la voz masculina, encontramos, como se observa en el gráfico 8 , que la primera es algo mejor evaluada tanto cognitiva como afectivamente $(4,67$ frente a 4,45 en la valoración general). 


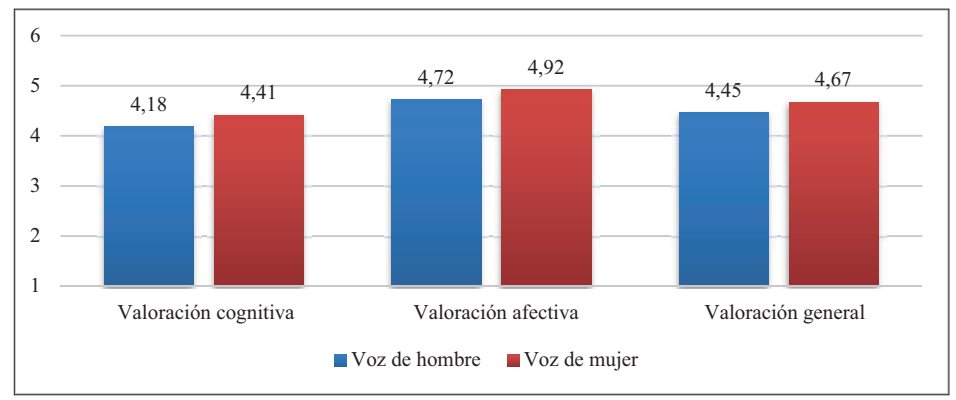

Gráfico 8. Valoración directa de la variedad propia: voz evaluada

No resulta relevante la influencia de las variables independientes sexo y edad cuando se hace la evaluación de las voces de los dos hablantes canarios. En ambos casos encontramos que la valoración general es idéntica $(4,6)$, aunque la afectiva es ligeramente superior en el grupo de los hombres y en los informantes más jóvenes ( 4,9 en los dos casos, frente al 4,8 de las mujeres y los sujetos de más edad) y la cognitiva lo es en el de las mujeres y en los sujetos de más edad: ambos grupos alcanzan un 4,4 de promedio, frente al 4,2 de los hombres y al 4,3 de los informantes más jóvenes. Por el contrario, la valoración directa según la formación recibida sí ofrece una diferencia que cabe destacar: los informantes que poseen estudios especializados valoran algo mejor que los otros la variedad canaria desde los dos puntos de vista. Estos datos se reflejan en el siguiente gráfico:

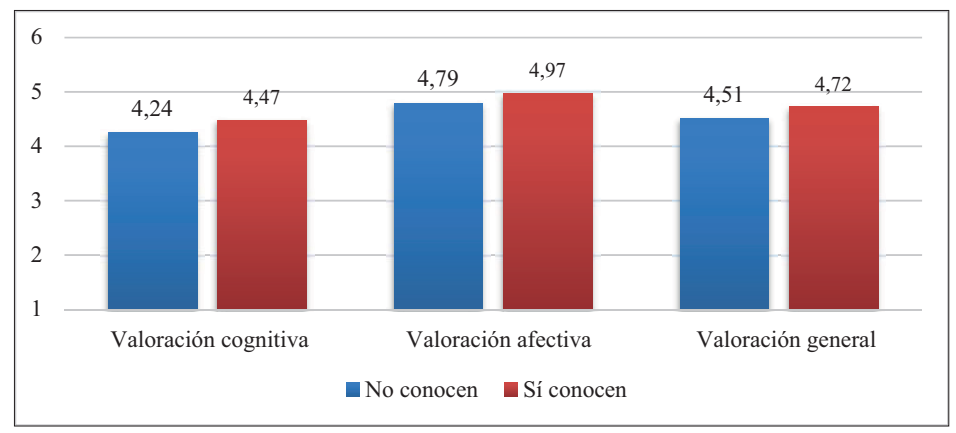

Gráfico 9. Valoración directa sobre la variedad propia según la variable formación en variedades

Una vez contemplados los promedios de valoración cognitiva y afectiva, interesa conocer qué aspectos lingüísticos concretos consideran los encuestados positivos y negativos en su propia variedad. En los siguientes 
gráficos se reflejan las respuestas de los informantes, y podemos afirmar, como primera conclusión, que el foco de atención se sitúa mayoritariamente en el plano fónico. Es algo que concuerda solo parcialmente con los resultados que obtuvo López Morales (2004: 266) en su estudio sobre conciencia sociolingüística en Puerto Rico; allí los informantes aportaron en mayor medida apreciaciones relacionadas con el nivel léxico (34,\%), si bien en segundo lugar aparecen los rasgos fónicos $(26,1 \%)$.

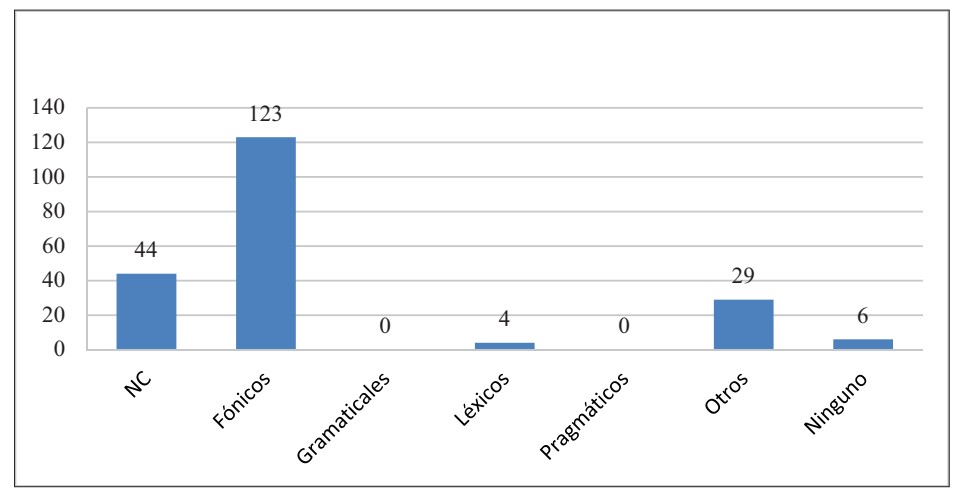

Gráfico 10. Aspectos positivos de la variedad propia

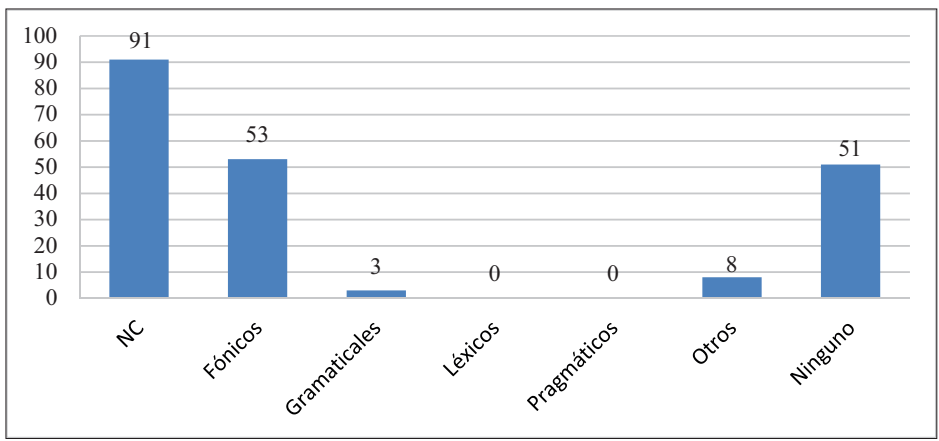

Gráfico 11. Aspectos negativos de la variedad propia

En cuanto a los rasgos positivos, es muy revelador que se incluyan aspectos como la aspiración de /s/ implosiva o el seseo, ambos con índices frecuenciales muy elevados. Estos datos pueden sorprender si se comparan con las respuestas obtenidas en la pregunta sobre el prestigio de las variedades, en la que solamente el $17,7 \%$ consideraba la modalidad canaria como la más prestigiosa. Realmente los estudios sobre el habla de 
Las Palmas de Gran Canaria ${ }^{12}$ indican que tanto un fenómeno como el otro forman parte importante de la norma del sociolecto alto urbano: no se anotan casos de distinción entre /s/ y / / /, por un lado; por otro, la aspiración es la realización ampliamente mayoritaria de los hablantes palmenses (incluso por encima del $90 \%$ en posición interna de palabra). Que la aspiración no es un rasgo estigmatizado lo demuestra el hecho de que los hablantes del nivel culto no aumentan el número de sibilantes con respecto al conjunto de sociolectos urbanos, pero sí se distinguen de los otros niveles por la proporción superior de realizaciones aspiradas frente al mayor número de elisiones de los otros grupos.

Otros rasgos fónicos considerados positivamente son la entonación y, también con una frecuencia elevada, la claridad. Por otro lado, como era de esperar por los resultados de múltiples investigaciones realizadas en distintas lenguas, los informantes no señalan ningún rasgo gramatical. En cuanto al léxico, poco destacado aquí, hemos de referirnos al valor positivo que algunos hablantes conceden al uso del dialectalismo guagua. Por último, las 29 respuestas que hemos clasificado como "Otros" aluden a cualidades como bonita, cercana, suave o agradable.

En el polo opuesto, en el de los aspectos que los informantes consideran negativos en las voces de los dos hablantes canarios (gráfico 11), resaltan las frecuencias obtenidas por la ausencia de respuesta y por la opción "Ninguno", que suman un $68,9 \%$. Entre los pocos rasgos negativos que se han recogido destacan nuevamente los fónicos (82,8\% de las respuestas específicas), pero en esta ocasión no hay ninguno que sobresalga de manera evidente: las respuestas más abundantes son las que aluden a la monotonía, a las que se unen algunas que resaltan la lentitud del habla; paradójicamente, en otros casos se hace referencia a la rapidez que caracteriza la voz evaluada. No faltan los ejemplos que consideran negativos algunos rasgos que otros informantes habían valorado positivamente, como la aspiración y el seseo, pero hemos de decir que son pocos los casos. Destacamos también que la pronunciación adherente de la /c/ fue apuntada por dos sujetos de la muestra.

Los resultados que estamos comentando sobre la valoración directa de las voces de dos hablantes canarios obligan a reflexionar sobre datos aparentemente contradictorios de nuestras encuestas. No obtenemos resultados similares cuando se enjuician concretamente enunciados reales, producidos por los hablantes de la región, que cuando se habla del canario (o de otras variedades) sin el soporte de las voces características de la

12 Vid., por ejemplo, Samper Padilla y Hernández Cabrera (1995). 
modalidad. Cabría preguntarse qué entienden los encuestados por "canario" cuando en diversas investigaciones (incluso al comienzo de la nuestra) se pregunta por su valoración sobre la pronunciación regional. Es probable que ante esas preguntas generales los encuestados recurran a estereotipos culturales que después no quedan (al menos, no han quedado en nuestra encuesta) refrendados en el momento de enfrentarse a unas voces concretas (que, insistamos en ello, reflejan el habla culta canaria). Habría que analizar qué entienden los informantes por "hablar canario"; su juicio relativamente negativo podría justificarse si para ellos la modalidad canaria se identifica con la empleada por los sociolectos bajos (o incluso con la imagen estereotipada que se da en ciertos programas humorísticos de carácter costumbrista).

\subsubsection{Valoración indirecta de la variedad canaria}

En este punto del cuestionario se pregunta a los informantes su opinión acerca de las características del hablante, por un lado, y de la región y la cultura a las que este representa, por otro. Se trata, por lo tanto, de valoraciones indirectas, en cuanto que estas cuestiones van encaminadas a profundizar en la actitud de los informantes hacia una variedad concreta, en este caso la propia.

\subsubsection{Valoración a través de la persona que habla}

La primera pregunta tiene que ver con las características socioculturales de los hablantes cuyas voces se están considerando.

\begin{tabular}{|l|l|c|}
\hline \multirow{4}{*}{ Trabajo } & Poco cualificado & $6,8 \%$ \\
\cline { 2 - 3 } Ingresos & Bien cualificado & $59,5 \%$ \\
\cline { 2 - 3 } & Altamente cualificado & $33,7 \%$ \\
\hline \multirow{3}{*}{ Estudios } & Bajos & $5,3 \%$ \\
\cline { 2 - 3 } & Medios & $57,3 \%$ \\
\cline { 2 - 3 } & Altos & $37,4 \%$ \\
\hline & Sin estudios & $1,5 \%$ \\
\cline { 2 - 3 } & Primarios & $3,4 \%$ \\
\cline { 2 - 3 } & Secundarios & $28,1 \%$ \\
\cline { 2 - 3 } & Universitarios & $67 \%$ \\
\hline
\end{tabular}

Tabla 4. Valoración indirecta de la variedad propia a través de la persona que habla: características socioculturales 
Los entrevistados consideran mayoritariamente que los representantes del dialecto canario son personas de estudios universitarios $(67 \%)$, con una buena cualificación profesional $(59,5 \%)$ y con ingresos medios $(57,3 \%)$. Por lo tanto, los sitúan en el nivel más alto en cuanto a la educación recibida y en el segundo de los estadios de ocupación y de renta. Los porcentajes pueden explicar la valoración positiva que hemos comentado en el apartado anterior.

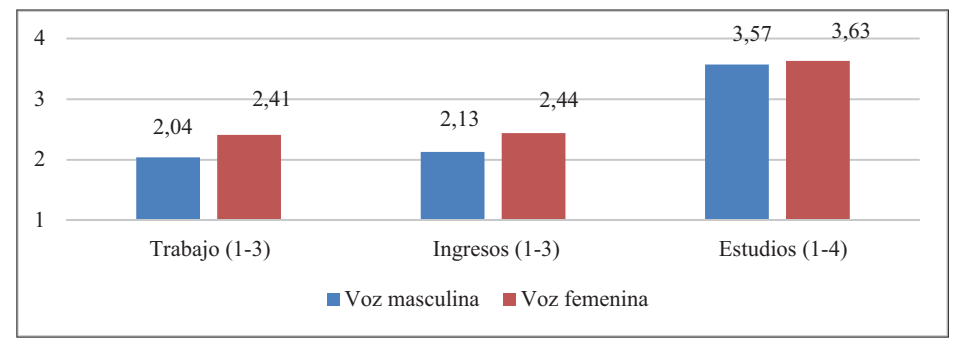

Gráfico 12. Valoración indirecta de la variedad propia a través de la persona que habla: características socioculturales. Voz evaluada

Cuando se contemplan las respuestas teniendo en cuenta la voz evaluada, se comprueba que la mujer destaca en todos los parámetros contemplados, si bien se observa una mayor igualdad cuando se considera el nivel de estudios.

El gráfico 13 muestra la valoración de las características personales de los dos hablantes canarios, valoración que podemos calificar como muy positiva:

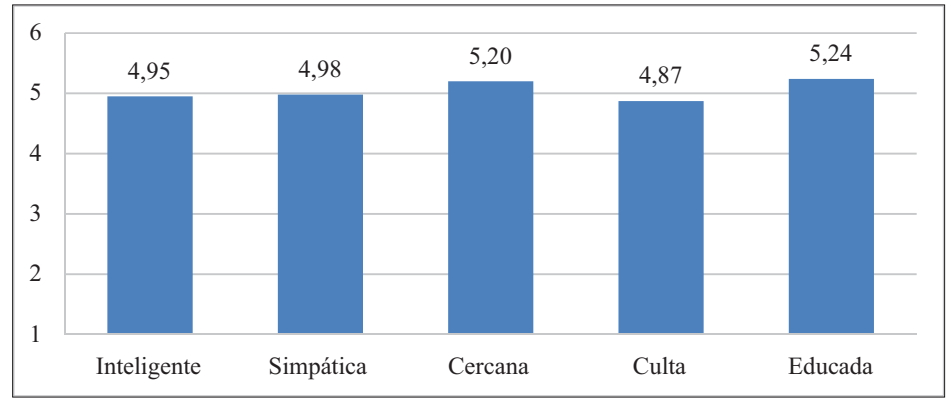

Gráfico 13. Valoración indirecta a través de la persona que habla: características personales

Todas las cualidades alcanzan promedios notablemente altos (entre 4,87 y $5,24)$, sin diferencias marcadas entre ellos. Podemos resaltar, no obstante, que las características que registran mejores promedios hacen referencia a la cercanía y a la educación, mientras que la relacionada con la cultura obtiene el promedio más bajo. 
Como se refleja en el gráfico 14, la mujer es siempre mejor evaluada que el hombre, que solo supera el 5 de promedio en los ítems 'cercano' y 'educado'. Las diferencias, en cualquier caso, no son abultadas (la voz masculina nunca baja del 4,6), y las más importantes se producen al valorar la simpatía y la cultura de ambos.

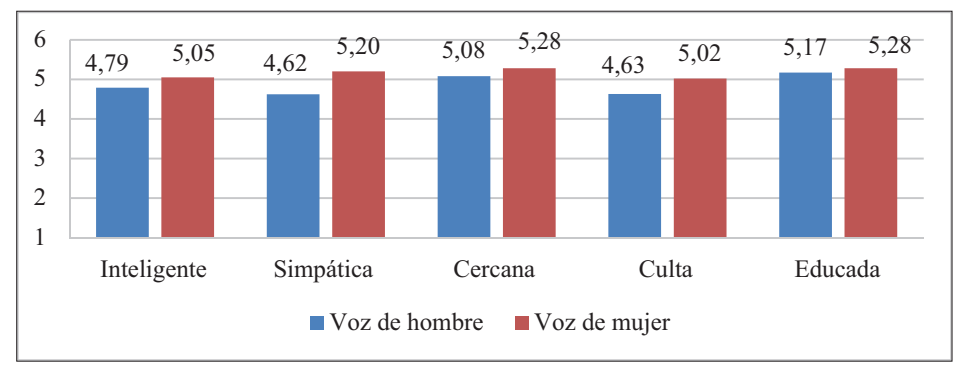

Gráfico 14. Valoración indirecta a través de la persona que habla: características personales. Voz evaluada

Las respuestas aportadas por los informantes cuando se les pregunta por su opinión sobre las personas de la región que están valorando son mayoritariamente positivas: entre otras, cercanas y simpáticas; gente relajada; son personas muy dadas, simpáticas, abiertas, habladoras; acento suave y dulce; léxico particular muy bonito. Tan solo se registran cuatro respuestas que encierran valoraciones ligeramente negativas:

- Soy canaria, asíque sé que hay todo tipo de personas aunque algunas tienen demasiado sentimiento regionalista con su acento.

- Hay todo tipo de personas, pero algunas tienen demasiado sentimiento regional con su acento.

- Gran parte es sencilla y simpática y gran parte es muy desagradable. Es una mezcla entre poca información y poco estudio y lo contrario. Es un lugar bastante diverso en ese sentido.

- Mucha gente bien formada y mucha gente inculta. Un lugar muy diverso. 
3.2.2.2. Valoración a través de la región

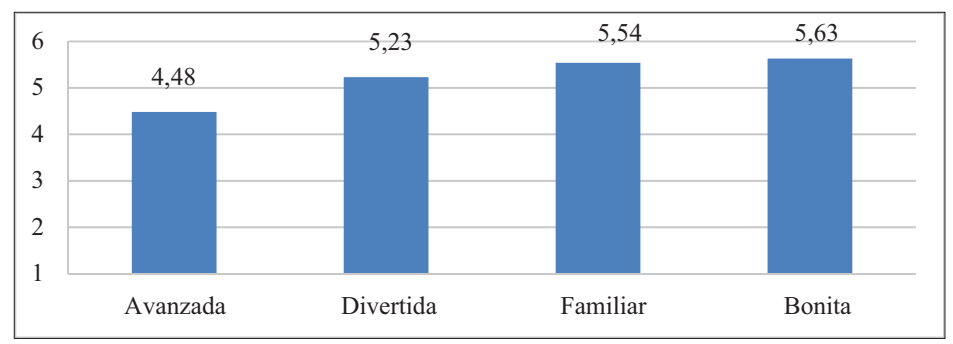

Gráfico 15. Valoración indirecta de la variedad propia a través de la región

A la hora de valorar la región de la que proceden los hablantes canarios, encontramos opiniones igualmente positivas. Los entrevistados consideran su región bonita $(5,63)$, familiar $(5,54)$ y divertida $(5,23)$; considerablemente inferior es el promedio que se otorga al carácter avanzado del archipiélago, que es el único aspecto que queda por debajo de 5.

Al revés de lo que sucedía en la evaluación a través de la persona, el gráfico 16 nos muestra que ahora el hombre recibe mejores valoraciones que la mujer en todos los aspectos, excepto en divertida, cualidad en la que se da una equivalencia entre ambos hablantes. A través de la voz masculina la región resulta para nuestros informantes más familiar, más bonita y más avanzada, aunque en este caso hemos de decir que las diferencias son mínimas.

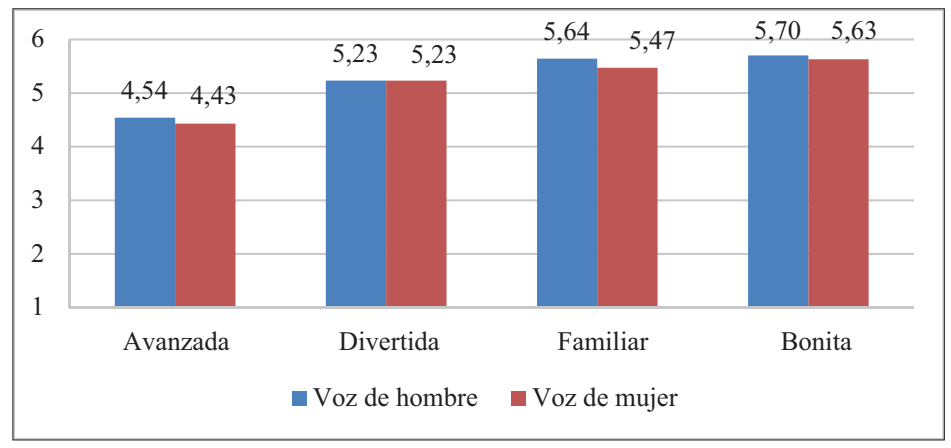

Gráfico 16. Valoración indirecta de la variedad propia a través de la región. Voz evaluada 


\subsubsection{Valoración a través de la cultura}

Como se observa en el gráfico 17, los informantes consideran la cultura canaria especialmente cercana e interesante, algo menos rica y considerablemente menos innovadora; se insiste, por lo tanto, en la misma línea que veíamos en el caso de la valoración de la región.

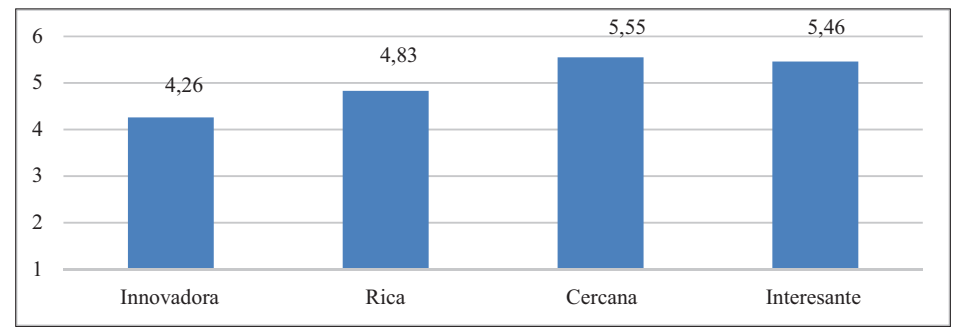

Gráfico 17. Valoración indirecta de la variedad propia a través de la cultura

Tampoco en lo que concierne a la cultura hay grandes diferencias cuando se juzgan separadamente las voces masculina y femenina. Esta última favorece que se considere una cultura más rica, pero recibe menos valoración en innovación y cercanía.

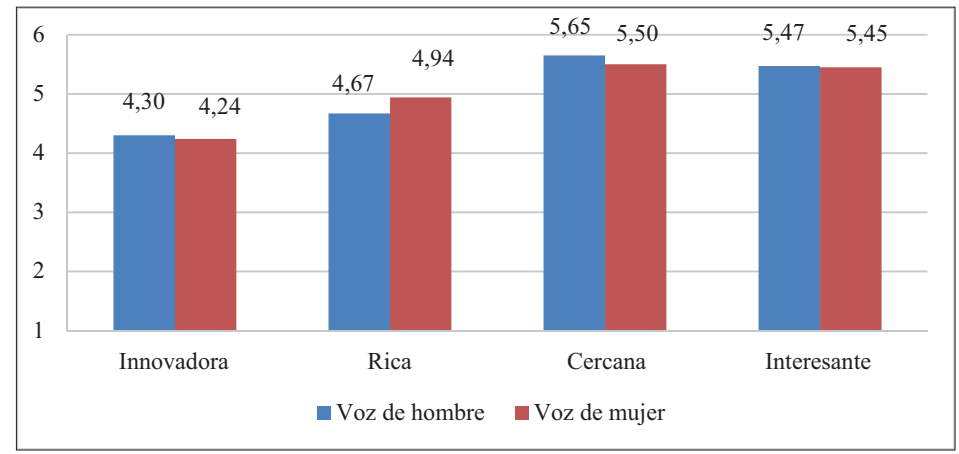

Gráfico 18. Valoración indirecta de la variedad propia a través de la cultura. Voz evaluada

\subsection{IDENTIFICACIÓN Y VALORACIÓN DEL RESTO DE LAS VARIEDADES}

En este último apartado se realizará una aproximación a la identificación y valoración del resto de las variedades que se contemplan en el proyecto. Recordemos que, además de la modalidad propia, los sujetos de la muestra evalúan las otras siete normas dialectales del español. En el gráfico 19 se 
reflejan los porcentajes de identificación de las variedades evaluadas por los estudiantes, incluida la canaria.

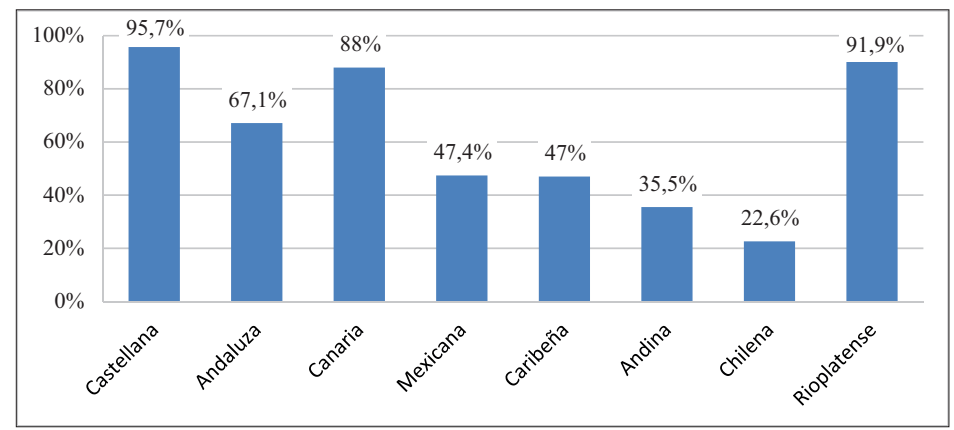

Gráfico 19. Identificación correcta de las variedades

Las variedades reconocidas en mayor medida han sido, por este orden, la castellana y la rioplatense; ambas superan el $90 \%$ de identificaciones correctas, proporciones explicables por la prominencia de ciertos rasgos fónicos muy peculiares. De esta forma se entiende que los porcentajes de reconocimiento sean superiores incluso al de las propias voces canarias. La modalidad que se reconoce en menor medida es la chilena, que en 29 ocasiones, como se vio anteriormente, se ha confundido con la canaria, es decir, con la variedad propia, y que en 45 casos es ubicada junto con las normas caribeñas.

Con respecto a la valoración directa que hacen los informantes sobre los aspectos afectivos y cognitivos, contemplados de manera conjunta, encontramos que la variedad mejor valorada es la canaria, a la que sigue muy de cerca la chilena.

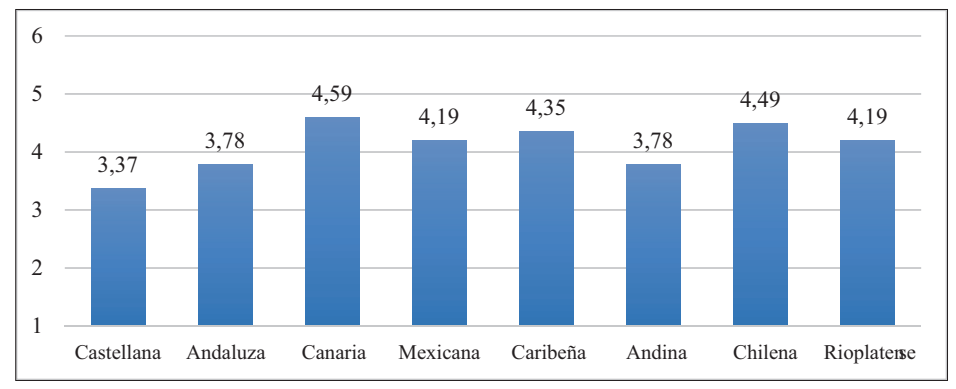

Gráfico 20. Valoración directa de las variedades 
Es curioso que las dos modalidades peninsulares, junto con el español andino, ocupen los últimos lugares en cuanto a la valoración que realizan los estudiantes canarios, y llama especialmente la atención el caso del castellano, que tan solo alcanza los 3,37 puntos de promedio. Este resultado contrasta abiertamente con la idea del castellano como variedad de prestigio, sostenida por casi el $44 \%$ de nuestros informantes. Son datos que confirman nuestra idea de que las preguntas sustentadas en la valoración de las voces regionales pueden aportar resultados muy diferentes a las que se formulan en abstracto, sin estar basadas en la audición de unas grabaciones concretas.

El análisis de manera diferenciada de los aspectos cognitivos y afectivos (gráfico 21) abunda en la valoración negativa que alcanza la variedad castellana: en los rasgos cognitivos solamente el andaluz y el andino obtienen promedios inferiores, mientras que en los afectivos ocupa la última posición y es la única modalidad que no alcanza los tres puntos de promedio. Se pone de manifiesto que los informantes canarios aprecian más las modalidades del español americano (con la excepción de la andina), a las que atribuyen valores más positivos tanto en lo cognitivo como en lo afectivo.

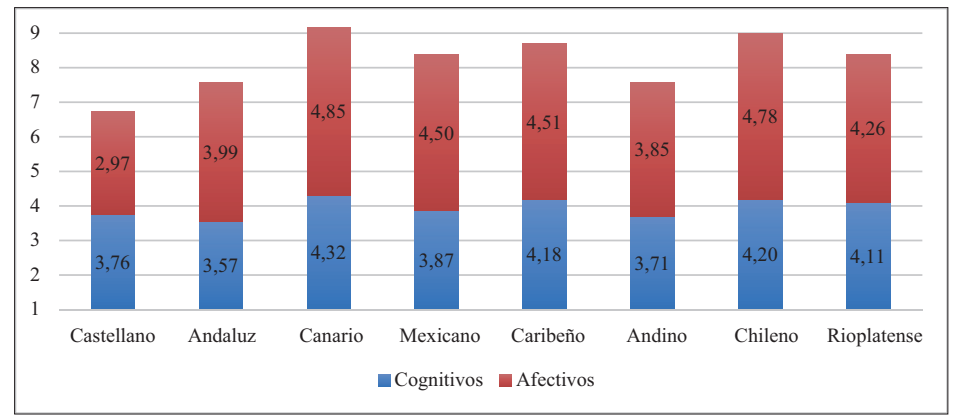

Gráfico 21. Valoración directa de las variedades. Aspectos cognitivos y afectivos

En el gráfico 22 se exponen los resultados que se obtienen cuando nuestros encuestados han evaluado las características socioculturales (puesto de trabajo, nivel de ingresos y nivel de estudios) que atribuyen a las personas que hablan. Son valoraciones lógicamente asociadas a la idea del prestigio. 


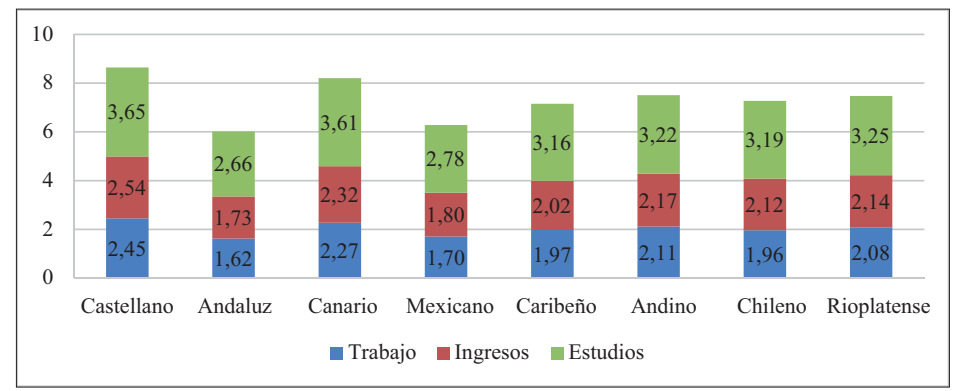

Gráfico 22. Valoración indirecta de las variedades a través de la persona que habla: características socioculturales

Hay que destacar ahora que es la castellana la variedad que alcanza la mejor puntuación global, seguida de cerca por la canaria. La tercera modalidad española, la andaluza, ocupa la última posición de todas las variedades contempladas. Entre las normas hispanoamericanas, se observa que la andina es la mejor considerada, seguida de cerca por la rioplatense, la chilena y la caribeña (en este orden). El español mexicano es el que peores promedios ha obtenido, aunque queda por encima del andaluz.

Es sintomático que dos de las variedades menos consideradas en función de los aspectos cognitivos y afectivos alcancen ahora promedios tan elevados. Es probable que los encuestados consideren marca de prestigio la pronunciación apicoalveolar de la/s/ que se escucha tanto en los audios de los representantes castellanos como en los de los andinos, en este caso antioqueños ${ }^{13}$.

Con el objetivo de profundizar en la comparación entre las tres variedades españolas recogemos en la tabla 5 los porcentajes de valoración diferenciados para los tres indicadores de base: puesto de trabajo, nivel de ingresos y nivel de estudios de los hablantes:

\begin{tabular}{|l|l|c|c|c|}
\hline & & Canario & Castellano & Andaluz \\
\hline \multirow{3}{*}{ Trabajo } & Poco cualificado & $6,8 \%$ & $2,3 \%$ & $41,4 \%$ \\
\cline { 2 - 5 } & Bien cualificado & $59,5 \%$ & $50,2 \%$ & $54,8 \%$ \\
\cline { 2 - 5 } & Altamente cualificado & $33,7 \%$ & $47,5 \%$ & $3,8 \%$ \\
\hline
\end{tabular}

13 Vid. la caracterización del español andino en Moreno Fernández (2009: 312). 


\begin{tabular}{|l|l|c|c|c|}
\hline \multirow{4}{*}{ Ingresos } & Bajos & $5,3 \%$ & $2,2 \%$ & $32,2 \%$ \\
\cline { 2 - 5 } & Medios & $57,3 \%$ & $41,9 \%$ & $62,6 \%$ \\
\cline { 2 - 5 } & Altos & $37,4 \%$ & $55,9 \%$ & $5,2 \%$ \\
\hline \multirow{3}{*}{ Estudios } & Sin estudios & $1,5 \%$ & $0,9 \%$ & $6,4 \%$ \\
\cline { 2 - 5 } & Primarios & $3,4 \%$ & $3,6 \%$ & $35 \%$ \\
\cline { 2 - 5 } & Secundarios & $28,1 \%$ & $25,2 \%$ & $44,6 \%$ \\
\cline { 2 - 5 } & Universitarios & $67 \%$ & $70,3 \%$ & $14 \%$ \\
\hline
\end{tabular}

Tabla 5. Valoración indirecta de las variedades españolas a través de la persona que habla: características socioculturales

En consonancia con los datos recogidos en el gráfico 22, se observa que los hablantes del español septentrional obtienen porcentajes más altos que los canarios en los niveles superiores de cada indicador, si bien es cierto que la diferencia en cuanto a los estudios no resulta tan marcada. Se comprueba, por lo tanto, que los informantes canarios, a pesar de que no valoran de manera positiva las voces castellanas ni desde la perspectiva cognitiva ni desde la afectiva, continúan situando la variedad septentrional en un rango superior desde un punto de vista social. Los resultados comparados de la variedad canaria y la castellana no muestran, sin embargo, unos porcentajes muy diferenciados (ambas ocupan, como vimos en el gráfico 22 , los dos primeros lugares en la valoración de todas las modalidades). Sí se encuentran diferencias importantes cuando se comparan los porcentajes de ambas variedades con los que ha obtenido la modalidad andaluza. Llama la atención que en el $41,4 \%$ de los casos se atribuya a los hablantes de esta variedad un trabajo poco cualificado, que en el $32,3 \%$ se mantenga que tienen un nivel de ingresos bajo y que en el $35 \%$ se opine que solamente tienen estudios primarios.

\section{CONCLUSIONES}

1. El 43,6\% de los sujetos de nuestra muestra considera que la variedad más prestigiosa es la castellana. En una proporción bastante menor aparece la opción que alude a la igualdad entre todas las variedades (con un $23,9 \%$ ), mientras que solo un $17,7 \%$ cree que el canario es la modalidad más prestigiosa. 
2. Se mantiene, pues, entre gran parte de nuestros informantes la creencia de que hay un modelo de lengua ideal y que ese modelo es el español septentrional. Esto supone que para muchos de los encuestados, la modalidad que utilizan es una variedad con un prestigio inferior al que otorgan a la llamada "pronunciación peninsular".

3. Ha de resaltarse, no obstante, que entre los encuestados con formación dialectal pierde bastante terreno (se pasa del 49,3\% al $34,8 \%$ ) la consideración del castellano como la modalidad más prestigiosa, aunque siga siendo la opción mayoritaria. En este sentido, si consideráramos conjuntamente las respuestas que aluden a la igualdad entre las variedades y aquellas en que no se contesta a la pregunta formulada directamente, sería superior el porcentaje de los informantes que no se inclinan por ninguna variedad $(36,9 \%)$. Este resultado incide en la importancia de una adecuada formación que insista en la idea de una efectiva igualdad entre todas las normas dialectales.

4. Es curioso que un $12 \%$ de los entrevistados no reconozca correctamente su propia modalidad; el porcentaje de aciertos es inferior al de la identificación de los hablantes castellanos y rioplatenses. También llama la atención que en 29 casos se consideren canarias las grabaciones chilenas.

5. Es relativamente alta $(4,59)$ la valoración directa sobre la propia modalidad, si bien es más elevada la afectiva $(4,85)$ que la cognitiva $(4,32)$. En esta última, los informantes dan una puntuación más alta a cualidades como la claridad, el carácter urbano y la suavidad, y mucho más baja a la rapidez y a la variedad, opiniones que parecen respaldar el tópico del "aplatanamiento" que se atribuye al canario. Los resultados de la valoración afectiva, muy positiva en todos los ítems, destacan que el hablar canario resulta especialmente cercano, agradable, bonito y sencillo.

6. Tiene mucho interés el análisis de los rasgos lingüísticos positivos y negativos que perciben los encuestados en las voces canarias analizadas. Hay que resaltar que en casi el $70 \%$ de los casos no se incluyen rasgos negativos al valorar el habla canaria. Los entrevistados destacan los aspectos fónicos y, entre ellos, sobresale la opinión positiva sobre el seseo y la aspiración de /s/ implosiva, dos rasgos muy destacados del español canario (y de gran parte del español atlántico).

7. Los resultados de la valoración directa de las voces chocan con los que había aportado la pregunta sobre dónde se habla mejor el español. 
Esto revela la importancia de la prueba auditiva de grabaciones representativas de los distintos dialectos como método que permite acceder a una valoración más real de las variedades, más allá de opiniones apriorísticas que en ocasiones se basan en estereotipos culturales.

8. Las valoraciones indirectas de la variedad, realizadas a través de las características de sus hablantes representativos y del juicio sobre la región y su cultura, son también marcadamente positivas.

9. De las ocho variedades contempladas, las que obtienen mejor valoración son la canaria y la chilena. Es curioso que el castellano, junto con el andaluz y el andino, ocupe los últimos lugares, con promedios bajos tanto en los aspectos cognitivos $(3,76)$ como, especialmente, en los afectivos $(2,97)$. Este resultado contrasta abiertamente con la idea del castellano como variedad de prestigio. Las modalidades del español americano alcanzan valores más positivos.

10. Frente a la escasa valoración del castellano que hemos señalado en el punto anterior, ha de resaltarse que esa modalidad vuelve a considerarse muy positivamente cuando se evalúan los rasgos sociales de sus hablantes. En este caso son los que alcanzan las mejores puntuaciones en los tres indicadores: puesto de trabajo, renta y estudios. Esta valoración contrasta abiertamente con la que los informantes canarios otorgan a la variedad andaluza. El español canario queda muy cerca del castellano y figura, según estos parámetros, como la segunda modalidad entre todas las variedades contempladas.

11. A lo largo del trabajo, hemos constatado que el castellano sigue manteniendo su alta consideración entre los hablantes canarios tanto cuando estos seleccionan la mejor variedad hispánica a partir de la pregunta general abierta como cuando evalúan el estatus social de sus hablantes. Sin embargo, esa valoración positiva no se refrenda cuando los entrevistados analizan las voces desde el punto de vista cognitivo y afectivo, parámetros en los que, contemplados de manera conjunta, la variedad septentrional se sitúa en la última posición. Hay, pues, una doble perspectiva sobre el castellano: la creencia de que es la mejor variedad y de que sus hablantes gozan de un elevado estatus social se opone a su consideración negativa a partir de preguntas sobre aspectos cognitivos y afectivos.

Por su parte, la modalidad canaria, a pesar del bajo porcentaje que obtiene, frente al castellano, cuando se trata de elegir la variedad que representa 
el mejor español, es muy bien evaluada cuando se analizan sus voces representativas, incluso en la valoración del estatus social. Hemos de tener en cuenta que las voces evaluadas corresponden a hablantes del nivel de instrucción alto, lo que implica que el hablante canario tiene una actitud positiva hacia los rasgos de su modalidad cuando son los propios de su norma culta (de hecho, se evalúan positivamente el seseo y la aspiración de $-/ \mathrm{s} /$ ). Las respuestas de nuestros informantes están manifestando un cambio importante en relación con el comentado "complejo lingüístico" de los canarios cuando juzgan manifestaciones concretas de su variedad culta y no recurren a la imagen estereotipada que refleja una extendida visión caricaturizada del habla regional.

Sin duda, la continuidad de este trabajo permitirá conocer más profundamente ese entramado de creencias y actitudes que manifiestan los hablantes canarios hacia su propia modalidad y hacia las otras normas hispánicas.

\section{REFERENCIAS BIBLIOGRÁFICAS}

Bentivoglio, Paola y Mercedes Sedano. 1999. Actitudes lingüísticas hacia distintas variedades dialectales del español latinoamericano y peninsular. En Matthias Perl, Klaus Pörtl, Araceli Marín Presno (coords.). Identidad cultural y lingüistica en Colombia, Venezuela y el Caribe hispánico, pp. 135-159. Tübingen: Max Niemeyer.

Blas Arroyo, José L. 2005. Sociolingüística del español. Desarrollos y perspectivas en el estudio de la lengua española en contexto social. Madrid: Cátedra.

Buzón García, José M., Begoña Gómez Devís y José R. Gómez Molina. 2017. Actitudes lingüisticas en Valencia y su área metropolitana. Estudio longitudinal y análisis de tendencias. Valencia: Tirant Humanidades.

Catalán, Diego. 1989 [1964]. El español en Canarias. El español. Orígenes de su diversidad, pp. 145-201. Madrid: Paraninfo.

Cestero Mancera, Ana M. ${ }^{a}$ y Florentino Paredes García. 2015. Creencias y actitudes hacia las variedades normativas del español actual: primeros resultados del Proyecto PRECAVES-XXI. Spanish in Context 12/2: 255-279.

2018. Creencias y actitudes hacia las variedades cultas del español actual: el proyecto PRECAVES XXI. Boletín de Filología (este volumen).

García de Diego, Vicente. 1978 [1946]. Manual de dialectología española, $3^{\mathrm{a}}$ ed. corregida y aumentada. Madrid: Ediciones Cultura Hispánica del Centro Iberoamericano de Cooperación.

Hernández Cabrera, Clara E. y Marta Samper Hernández. 2011. Rasgos fónicos regionales en los noticiarios de la televisión autonómica canaria. La velarización de la nasal final. En Raúl Ávila (ed.). Variación del español en los medios, pp. 267-288. México DF: El Colegio de México. 
y José Antonio SAmper Padilla. 2018. Un acercamiento a la pluralización de haber en la prensa canaria. En Lynn Williams (ed.). Estudios de lexicografía y lexicología españolas. Homenaje al profesor doctor D. Orlando Alba, pp. 71-99. Bern: Peter Lang.

Hernández Hernández, Humberto. 2009. Norma lingüistica y español de Canarias. Manual de consulta para periodistas. Santa Cruz de Tenerife: Gobierno de Canarias, Consejería de Educación, Universidades, Cultura y Deportes y Dirección General del Libro, Archivos y Bibliotecas. Asociación de la Prensa de Santa Cruz de Tenerife.

Johannessen-Toft, Janne H. 2007. Actitudes lingüísticas de los hablantes de Las Palmas de Gran Canaria hacia su propia habla. Memoria final de máster, Universidad de Bergen.

López Morales, Humberto. 2004. Sociolingüistica, $3^{\mathrm{a}}$ ed. aumentada. Madrid: Gredos.

Morgenthaler García, Laura. 2008. Identidad y pluricentrismo lingüístico. Hablantes canarios frente a la estandarización. Madrid-Frankfurt: Iberoamericana-Vervuert.

Moreno Fernández, Francisco. 2009. La lengua española en su geografía. Madrid: Arco Libros.

Morera, Marcial. 1990. Lengua y colonia en Canarias. La Laguna: edición propia.

1995. En defensa del habla canaria. Tenerife: Asociación para la Academia Canaria de la Lengua.

Ortega Ojeda, Gonzalo. 1981. El español hablado en Canarias. Visión sociolingüística. Revista de Filología de la Universidad de La Laguna 0: 111-116.

1996. ¿Puede hablarse de una norma lingüística culta en Canarias? La enseñanza de la lengua española en Canarias. Algunas perspectivas, pp. 53-69. La Laguna: Instituto de Estudios Canarios.

SAmper Padilla, José Antonio. 2008. Sociolinguistic aspects of Spanish in the Canary Islands. International Journal of the Sociology of Language 193/194: 161-176.

y Clara E. Hernández Cabrera. 1995. La variación de -/s/ en el español culto de Las Palmas de Gran Canaria: condicionantes lingüísticos. Philologica Canariensia 2: 391-408.

y Clara E. Hernández Cabrera. 2007. La variación de -/s/ en los programas informativos de televisión en las Islas Canarias. En Pedro Barros García, Gonzalo Águila Escobar y Esteban T. Montoro del Arco (eds.). Estudios lingüísticos, literarios e históricos. Homenaje a Juan Martínez Marín, pp. 349-361. Granada: Universidad de Granada.

y Clara E. Hernández Cabrera. 2011. La elisión de -d- intervocálica en los informativos de la Televisión Canaria: comparación con los datos del PRESEEA. En Raúl Ávila (ed.). Variación del español en los medios, pp. 289-312. México DF: El Colegio de México.

Trujillo, RAmón. 1981. Algunas características de las hablas canarias. Estudios colombinos, pp. 11-24. La Laguna: Universidad de La Laguna. 